Cad.Est.Ling., Campinas, (42): 89-97, Jan./Jun. 2002

\title{
SOBRE A ESPECIFICIDADE DA PESQUISA NO CAMPO DA PRAGMÁTICA
}

[.....] to talk of 'natural languages' as objects that can both be studied empirically and have theorems proved about them is acknowledged nonsense.

— P.H. Matthews (1982: 9)

\author{
KANAVILLIL RAJAGOPALAN \\ DL-IEL/UNICAMP
}

\section{PRAGMÁTICA COMO UM 'COMPONENTE' DA TEORIA LINGÜÍSTICA: UMA HERANÇA DE UTILIDADE DUVIDOSA}

É preciso que se diga, antes de qualquer coisa que, a despeito de todos os desmentidos e afirmações em contrário, muitos pragmaticistas ainda se sentem, eles próprios, um tanto acuados e tomados por uma espécie de 'complexo de inferioridade' quando alguém levanta a questão da cientificidade do seu empreendimento. Não é difícil perceber que os pragmatistas de hoje são apenas herdeiros de uma preocupação que sempre marcou a lingüística desde o seu momento inaugural como moderna ciência da linguagem - a saber, o desejo de reivindicar para si o caráter científico. Acontece que, no momento histórico em que a lingüística se consolidou como uma disciplina autônoma, a concepção de ciência que contava com o maior prestígio era a abordagem neo-positivista. Nos EUA, por exemplo, um dos textos mais importantes de Leonard Bloomfield-Linguistic Aspects of Science (Bloomfield, 1939) foi divulgado na série International Encyclopedia of Unified Science que servia de baluarte da postura positivista em matéria de ciência. Nas palavras de Robins (1981: 7),

O termo ciência tem sido usado na definição de Lingüística Geral. Ele pode ser entendido de duas maneiras. Em termos mais amplos, refere-se ao fato de que o estudo da língua em geral e de línguas em particular, [...] é meritório de atenção dos pesquisadores, e que um corpo sistemático de fatos e teorias está constituído ao seu redor. Em termos mais específicos e particulares, indica a atitude tomada hoje pelo lingüista na direção de seu objeto de estudo, e nisto, talvez, ela marque uma característica definida da Lingüística do século XX.

É claro que, vez por outra, encontramos na literatura desabafos espontâneos como o de Robin Lakoff (1989: 984):

Eis, a nosso ver, a maior e mais atordoante pergunta: A lingüística é, afinal, uma ciência? Se não for, o que acontece? Antes de enrijecer os músculos de sua mandíbula, pense um pouco: 
Será que queremos que a nossa área seja uma 'ciência' porque isso traz prestígio para o nosso empreendimento e nos dá a sensação de estarmos fazendo algo que vale a pena fazer, ou será que realmente há justificativas para a nossa decisão?

Por outro lado, há quem se apresse para decretar e celebrar a não-cientificidade das pesquisas em pragmática. Vejamos o que diz Cook (1990: 15) a esse respeito:

A filosofia pragmática não é, ao contrário do que se supõe com freqüência, uma técnica pronta para analisar o discurso em funcionamento [....]. É preciso reconhecer a natureza subjetiva, seletiva e fundamentalmente não científica das análises da linguagem em seu contexto e não disfarçá-la, recorrendo aos símbolos e signos das abordagens mais seguras (ainda que menos empolgantes).

O problema com tal atitude perante a natureza da pragmática não está na afirmação de que a pragmática requer métodos e técnicas de análise diferentes daqueles adotados em outros campos de pesquisa (o que é inteiramente procedente ou, ao menos, admissível enquanto argumento), mas na franca admissão de que a cientificidade esteja ao lado daqueles que trabalham com outras orientações. Isto é, por um lado devemos aplaudir a iniciativa por parte de pesquisadores como Lakoff e Cook no sentido de ressaltar a especificidade da pesquisa no campo da pragmática. Por outro lado, precisamos estar também atentos à tendência de sempre comparar o trabalho no campo da pragmática com as práticas adotadas em outras áreas dentro da lingüística—como se não houvesse nenhuma saída para a pragmática a não ser trilhar o caminho já aberto pelas áreas 'mais nobres'.

\section{O PRAGMATISTA E SEU 'COMPLEXO DE INFERIORIDADE'}

Alias, é de se notar que quase não se discute mais o caráter científico dos trabalhos feitos nos campos da sintaxe e da semântica. Nesses campos do saber, o caráter científico dos procedimentos adotados é aceito sem qualquer questionamento. Já no campo da pragmática a situação é bem diferente. Não é incomum encontrar na literatura um pesquisador que se sente na obrigação de defender o rigor científico das análises que propõe. Assim, quando uma estudiosa como Ter Meulen (1988: 439) afirma que "A Pragmática, embora de forma menos marcante que a Sintaxe e a Semântica, é caracterizada por um conjunto de questões centrais de pesquisa que formam um programa cientifico coerente de investigação lingüística", devemos nos ater à ressalva feita pelas palavras 'embora de forma menos marcante' e perguntar por que tal modalização? E por que tanta ânsia no sentido de equiparar a Pragmática à Sintaxe e à Semântica? Por que razão se subentende que a cientificidade da pesquisa desenvolvida sob o rótulo de pragmática precisa ser cotejada e comparada com aquela que se supõe que seja alcançável nos campos da sintaxe e da semântica (e nesta mesma ordem)?

O que se dá a entender na afirmação da autora mencionada acima é que à Pragmática cabe a nobre tarefa de seguir os passos dos demais componentes da velha tríade semiótica e contentar-se com as sobras das análises feitas neles. Ou seja, o que 
ainda norteia a imagem do campo da pragmática é a divisão tripartite do campo geral que se preocupa com o estudo de signos, a saber, a semiótica. Ainda se referindo à citação feita há pouco, está também muito patente a idéia de que a Pragmática é vista, até mesmo por muitos aqueles que optaram por trabalhar nela, como um campo de pesquisa onde as análises são menos rigorosas que nos outros campos e onde os resultados também acabam se mostrando menos palpáveis e previsíveis. Em suma, a Pragmática é ainda vista por muitos como uma 'terra de ninguém' ou melhor, um "terreno baldio" onde se despejam os detritos provenientes dos demais campos (Escondido, é claro, dos olhares públicos, uma vez que há aterros sanitários apropriados para tal finalidade).

\section{A PRAGMÁTICA COMO CAMPO DE SOLUÇÕES 'MILAGROSAS'}

É bem verdade que, para muitos pesquisadores, a pragmática está aí para salvar uma dada tentativa explanatória quando os “dados' se revelam irritantemente rebeldes e persistem em desafiar a explanação proposta, seja no campo de sintaxe, seja no de semântica. Não são poucos os pesquisadores que apelam para o Princípio de Cooperação proposto por Grice (1975) como a saída milagrosa para tratar dos problemas que não foram solucionados nos outros campos. $\mathrm{O}$ recém falecido lingüista norte-americano James McCawley se rebelou de tal forma contra tal saída fácil preferida por muitos dos seus colegas que chegou a sugerir, com toda a ironia a que tem direito, que seja adotada como lema pelos adeptos de Grice e estampada num adesivo para os seus automóveis a frase "Grice salva". Ou seja, acredite piamente no poder miraculoso da teoria griceana, com todas as suas máximas e salvaguardas, e, de uma forma ou de outra, você conseguirá se livrar do impasse encontrado no seu arcabouço explanatório. A sua contribuição para diálogo em curso não deve ser lacônica demais nem prolixa em demasia. Cabe a cada participante zelar pelo princípio de cooperação, a menos que haja boas razões para se desviar do comportamento pré-estabelecido. Tamanha é a margem de manobra que a teoria propicia que na verdade o preceito griceano serve de coringa, pronta para ser lançada em qualquer situação emergencial.

O lado jocoso da observação de McCawley à parte, permanece o fato de que a pragmática é convocada, com muita freqüência, a fim de aparar o resultado de trabalhos feitos em outras áreas, notadamente a sintaxe e a semântica. Ou seja, relegam-se ao campo de pragmática todos aqueles pequenos 'problemas' que sobraram das análises em outras áreas. O frequiente recurso ao famigerado 'contexto' é prova disso. $\mathrm{Na}$ verdade, é para se valer da noção de contexto é que a pragmática é lembrada com freqüência por pesquisadores em outras áreas de lingüística. Afinal uma boa parte das teorias pragmáticas tem como questão central a questão do contexto. Nas palavras de Ochs (1979: 2):

Um conceito chave nas abordagens pragmáticas à linguagem é o de "contexto". A própria Pragmática se interessa pelas diferentes formas pelas quais o contexto intervém para elucidar as expressões e a compreensão de proposições pelos usuários de língua numa dada comunidade [2] 
Os trabalhos que foram inspirados pela teoria de Grice e que procuram aperfeiçoar os insights contidos naquela abordagem teórica (Lewis, 1969; Schiffer, 1972; Horn, 1984) primam pela ambição de unificar todo o arcabouço, se possível reduzindo-o a um único princípio. A tentativa mais célebre e, com certeza, a mais bem sucedida, tem sido a de Sperber e Wilson (1986). Trata-se, como Levinson (1989: 469) a caracteriza, de nada mais e nada menos que uma ambiciosa investida que objetivava uma verdadeira mudança de paradigma no campo de pragmática. E a mudança no caso tinha a ver com o esforço de "deslocar o centro de gravidade da teoria pragmática, localizando-a firmemente numa teoria geral de cognição" (Levinson, 1989: 455). Ou, como dizem os próprios Sperber e Wilson (1986: 193), o propósito de comunicação não é "reduplicar os pensamentos", mas, sim, "ampliar os ambientes cognitivos mútuos".

Por mais louváveis que sejam as tentativas como a de Sperber e Wilson, é preciso frisar que elas se enquadram num velho sonho de todas as ciências- $\mathrm{o}$ de reduzir todo um arcabouço a um punhado de princípios ou, como no caso específico em pauta, a um único princípio. No lugar de máximas de Grice, tem-se um único princípio. Dizem Sperber e Wilson (1986: 162): “Os comunicadores não 'seguem' o princípio de relevância; e eles jamais poderiam violá-lo mesmo se assim o quisessem. O princípio de relevância se aplica sem exceções [....]”. O princípio de relevância é, dessa forma, elevada a um estatuto comparável às leis de mudança sonora proposta pelos neogramáticos do século XIX. Essas leis eram tidas como 'cegas' uma vez que não admitiam exceções. Como chegou a comentar Labov (1981: 273):

Os estudiosos continuam a procurar princípios universais por meio da manipulação de exemplos isolados—-subtraindo do conjunto de dados disponíveis, ao invés de acrescentar.

[2]

O resultado desse esforço de identificar a qualquer custo princípios universais é resumido nas seguintes palavras de Talbot (1993:7):

[...] as pessoas são representadas como indivíduos que se deparam com problemas inusitados no processo de comunicação. No mundo real, porém, as pessoas são seres sociais que se encontram em condições pré-existentes (socialmente determinadas).

Em nome de princípios universais, Sperber e Wilson fazem vista grossa a todo um conjunto de fatores de ordem social e cultural que sabidamente influenciam a forma como as pessoas se interagem entre si. Como argumenta Cummings (1998), a proposta de Sperber e Wilson padece de um reducionismo científico exacerbado que é, na opinião da autora, o legado mais duradouro do positivismo lógico.

\section{A PROPOSTA DE VERSCHUEREN}

Num trabalho recente, Verschueren (1999) sugere que até mesmo o próprio gesto de tentar definir a pragmática como um componente da teoria lingüística se configura, quando submetido a uma análise cuidadosa, como um passo 'institucionalizante' que 
serve para demarcar e controlar os limites de um território dentro do qual se possa desenvolver determinadas linhas de pesquisa. Verschueren levanta essa questão no contexto de uma discussão sobre o potencial crítico da Pragmática, discutido nos últimos tempos por vários pragmatistas, entre os quais, notadamente, Jacob Mey que, já em seu livro de 1985, nos alertava sobre o fato de que "a maneira como usamos a linguagem concretiza interesses dominantes da sociedade, ajudando a oprimir uma grande parcela da população" (Mey, 1985: 16). Para Mey, assim como um número crescente de outros pesquisadores, há portanto uma necessidade urgente de assumir uma postura crítica diante do uso que fazemos da própria linguagem. Caso contrário, estaremos simplesmente legitimando tais interesses dominantes e até contribuindo para sua manutenção e perpetuação.

Verschueren, no trabalho acima referido, nos lembra com muita propriedade que “o uso da linguagem” a que alude Mey inclui não só seu uso nas situações do dia-a-dia, mas também-e por que não?-seu uso no discurso científico, nas ciências humanas e sociais, inclusive a própria Pragmática (Verschueren, 1999: 871). A pesquisa no campo da pragmática é, em outras palavras, regida pela condição daquilo que Benveniste chamou de 'sui-referencialdade'-isto é, a capacidade de algo para se referir a si próprio. Isso quer dizer que uma postura crítica em relação ao uso da linguagem terá de se desdobrar sobre a própria disciplina que reivindica o uso da linguagem como objeto de estudo. Em se tratando da postura crítica perante a linguagem, a Pragmática não pode se dar ao luxo de ficar isenta do próprio olhar crítico. A desculpa freqüentemente invocada para reivindicar neutralidade científica - a de que se trata de um exercício de metalinguagem e, portanto livre de uma possível contaminação a partir da linguagem objeto-simplesmente não está disponível para o pragmatista, e por tabela, nem para qualquer lingüista que reconheça a importância de fatores pragmáticos em seu trabalho. Em outras palavras, a Pragmática não tem como se contentar com o papel de uma disciplina meramente descritiva. Explanação na Pragmática necessariamente passa por uma série de questões que não dizem respeito à língua stricto sensu, e que, no entanto, fazem parte de qualquer esforço de abordar a linguagem no seu aspecto irredutivelmente social.

\section{A PRAGMÁTICA E OS DESDOBRAMENTOS DA SUA 'SUI-REFERENCIALIDADE'}

Podemos levar ainda adiante a questão do engajamento do pragmatista no seu trabalho de pesquisa e do pleno reconhecimento por sua parte do seu envolvimento no objeto de estudo escolhido: o uso da própria linguagem que ele/a é obrigado/a empregar enquanto 'instrumento' de sua análise. Sem dúvida, conforme vimos, tem-se a consequiência de que a distinção objeto de estudo/instrumento de análise simplesmente não está ao alcance do pragmatista que queira reivindicar para seu trabalho objetividade científica da forma que se imagina encontrar em outros campos de investigação lingüística. Contudo a consequiência mais impressionante disso tudo é a de que, o trabalho de pragmatista, pela própria natureza do fenômeno que foi escolhido como 
objeto de estudo, exige que o pesquisador se posicione de forma crítica no seu trabalho. A impossibilidade de assumir uma postura científica neutra se traduz na absoluta necessidade de se posicionar politicamente em suas pesquisas. As questões éticas e políticas não são meros desdobramentos das posições teóricas assumidas a serem explorados num momento posterior oportuno; elas estão aí a toda hora na pesquisa pragmática e, por conseguinte, em qualquer abordagem lingüística que dá lugar de destaque aos fenômenos pragmáticos. A pragmática, enquanto área de estudo e pesquisa, se situa no campo mais abrangente que podemos denominar de "a concepção ético-política da linguagem".

\section{A OBRIGAÇÃO DO COMPROMISSO POLÍTICO E ALGUMAS TÁTICAS UTILIZADAS PARA SE ESQUIVAR DELA}

É preciso, todavia, perguntar por que idéias como a defendida por Mey, Verschueren e tantos outros em relação à necessidade de adotar uma postura crítica (por tanto, a fortiori, política) na pragmática ainda não são aceitas como ponto pacífico pela comunidade acadêmica como um todo. É impressionante constatar que ainda há quem pense que a pesquisa pragmática pode e deve ser conduzida de forma neutra e ideologicamente descompromissada. Há quem queira simplesmente esvaziar a pragmática, tratando-a como um epifenômeno de importância secundária (Perkins, 1998). O que sobraria no caso seria a velha semântica veri-funcional, onde considerações éticas e ideológicas não teriam lugar algum, dada a crença na total isenção da lógica em relação a valores sócio-culturais.

O próprio Verschueren chega a pleitear que a pragmática seja vista como "nada senão uma 'perspectiva' específica sobre a linguagem" (Verschueren, 1999: 872-3). E acrescenta: "Isso não só resolveria a maioria dos problemas de delimitação [do campo], como também poria em cheque as tendências imperialistas e segregacionistas (ainda que, num mundo dirigido por interesses mercadológicos e não conteudísticos, uma dessas tendências seja necessária para se obter dinheiro, empregos, ou ambos)" (Verschueren, 1999: 872-3). Todavia, a proposta apresentada por Verschueren é problemática e, o que vem a ser pior, está em flagrante conflito com a sua própria idéia de que o trabalho em pragmática terá que se voltar para si mesmo na medida em que falar sobre a linguagem é apenas mais um dos usos da linguagem que o pragmatista se propõe a estudar. Isto é, o pragmatista não pode se contentar em definir sua área como simplesmente uma questão de 'perspectiva' como quer Verschueren, pois isso implicaria que se trata apenas de uma simples opção no que tange ao ponto de vista a ser assumido e que, a rigor, tanto vale adotar esta ou aquela perspectiva. Pelo contrário, pela sua própria insistência em que a pragmática se volta para ela mesma, rompendo com a barreira imposta entre a linguagem objeto e a metalinguagem (barreira esta aceita como tal e considerada como insuperável em, por exemplo, a maioria das correntes teóricas em semântica formal), Verschueren está obrigado a aceitar a consequiência de que o trabalho do pragmatista é diferente do dos seus colegas em outros campos da lingüística. 


\section{UMA PRAGMÁTICA DA CONDIÇÃO (E NÃO COGNIÇÃO) HUMANA}

A opção por trabalhar com a pragmática acarreta uma série de compromissos, inclusive de ordem política. Pois, no fim das contas, o que a pragmática objetiva desvendar é a própria condição humana, enquanto que os modelos de análise de ambição formalista adotam como meta o papel da linguagem na cognição (ou, da cognição na linguagem).

Desvencilhada da sua condição historicamente herdada de um campo de pesquisa à sombra de outros tidos como mais "nobres", a pragmática hoje se mostra cada vez mais apta a se integrar na luta social. Para Mey (1993:304),

$\mathrm{O}$ interesse crescente na pragmática como uma ciência da linguagem orientada para o usuário naturalmente nos leva à pergunta: Em que sentido a pragmática seria útil para os usuários? Mais especificamente, posto que uma parcela significativa dos usuários de qualquer língua está em situação desigual em relação à sua língua, e num nível mais profundo, por causa da posição de desigualdade na sociedade, parece razoável supor que um entendimento das causas da desigualdade social pode despertar uma maior compreensão do papel da linguagem nos processos sociais e, conversamente, uma consciência renovada da linguagem como expressão da desigualdade social pode nos conduzir em direção àquilo que é com frequiência chamado de uso 'emancipatório' da linguagem.

Ou seja, o pesquisador na área de pragmática está cada vez mais consciente do papel que exerce, não só como um estudioso que se interessa pelo funcionamento da linguagem na vida cotidiana dos usuários, mas na qualidade de alguém que, ao conduzir seu trabalho, desempenha a função de agente causador de mudanças sociais, mudanças essas que são postas em curso no momento exato em que são trazidas à baila as desigualdades que permeiam a realidade social sob a sua mira e-mais importante ainda - chega-se à percepção de que, em muitos casos, as desigualdades verificadas têm suas origens naquilo que Habermas chama de "distorções sistemáticas de comunicação".

A título de ilustração dessa nova tendência que desponta no horizonte das pesquisas em curso, podemos citar o trabalho interessante sendo desenvolvido pelo pensador sérvio Slavoj Zizek. Ao se debruçar sobre a questão de ideologia no mundo pós-queda-do-muro, Zizek insiste em que ela está muito presente na nova ordem mundial a despeito de alguns intelectuais de grande repercussão na mídia que querem propagar a idéia de que, com o fim da "guerra fria" já não há mais lugar no mundo para a ideologia. Para Zizek (1974), a forma como a ideologia opera no mundo globalizado em que vivemos é muito mais sutil e difícil de se detectar. Para começar, já não servem mais as velhas definições de ideologia como "falsa consciência". Isso por que, diz Zizek, raciocinando com os recursos provenientes da teoria de atos de fala (Searle, 1969), as mentiras são veiculadas e divulgadas pela grande mídia a nível ilocucionário e não, como prevê a pragmática ortodoxa, em nível do conteúdo proposicional. É possível hoje em dia mentir contando uma verdade. Isto é, o que torna uma grande mentira, por exemplo, a justificada mais comum dada pelas nações ricas do hemisfério 
norte ao impor sanções contra as exportações dos países do terceiro mundo não é que ela contém uma afirmação falsa, mas o fato de que uma constatação que inquestionavelmente verdadeira é invocada para justificar uma política discriminatória e não-como aparentemente querem que acreditemos-para promover o bem estar geral dos povos. Trata-se da acusação freqüentemente feita a respeito de trabalho escravo ou trabalho infantil em determinados países. Para Zizek, é preciso ficar atentos à falsidade ideológica praticada no nível ilocucionário nesses casos, pois verdades estão sendo utilizadas para escamotear interesses ideológicos inconfessáveis por justamente aqueles que, em situações análogas, já mostraram capazes de fazer vista grossa a outras tantas formas de exploração e injustiça, alegando como justificativa para tais "interesses estratégicos".

O uso que Zizek faz da teoria dos atos de fala é apenas um caso de como as teorias pragmáticas estão sendo exploradas e, ao mesmo tempo, estendidas em direções pouco imaginadas pelos seus expoentes originais. Ao mesmo tempo, isso sinaliza para um alargamento do campo de interesse da pragmática e interesse crescente no campo que atrai pesquisadores de outras áreas e preocupações.

\section{AGRADECIMENTOS}

Sou grato ao CNPq pela concessão da bolsa de produtividade em pesquisa - processo n. ${ }^{\circ} 306151 / 88-0$.

\section{$\overline{\text { REFERÊNCIAS BIBLIOGRÁFICAS }}$}

BLOOMFIELD, L. (1939). Linguistic Aspects of Science. International Encyclopedia of unified science. Vol. 1. $n^{\circ}$ 4. Chicago: University of Chicago Press.

COOK, G. (1990). 'Transcribing infinity: problem of context presentation'. Journal of Pragmatics. Vol. 14. $\mathrm{n}^{\mathrm{o}}$ 1. Pp. 1-24.

CUMMINGS, Louise. (1998). 'The scientific reductionism of relevance theory: the lesson from logical positivism'. Journal of Pragmatics. Vol. 29. nº 1. Pp. 1-12.

HORN, Lawrence.R. (1984). Toward a new taxonomy for pragmatics inference: Q-based and R-based implicature'. In D. Schiffrin (Ed.). (1984). Georgetown University Round Table on Languages and Linguistics 1984. Washington, DC: Georgetown University Press. Pp. 11-42.

LABOV, William. (1981). 'Resolving the Neo-grammarian controversy'. Language. Vol. 57. $\mathrm{n}^{\circ}$ 2. Pp. 267308.

LAKOFF, Robin. (1989). 'The way we were; or the real actual truth about generative semantics. A memoir'. Journal of Pragmatics. Vol. 13. nº 6. Pp. 939-998.

LEVINSON, S. (1989). 'A review of relevance'. Journal of Linguistics. Vol. 25. nº 2. Pp. 455-472.

LEWIS, David. (1969). Convention. Cambridge, Mass.: Harvard University Press. 
MATTHEWS, P.H. (1982). 'Formalization'. In Crystal, D. (Ed.) (1982). Linguistic Controversies. Londres: Edward Arnold Pub. Ltd.

MEY, Jabob. (1985). Whose Language? A study in Linguistic Pragmatics. Amsterdam: John Benjamins.

PERKINS, Michael R. (1998). ' Is pragmatics epiphenomenal? Evidence from communication disorders'. Journal of Pragmatics. 29. Pp. 291-311.

ROBINS, R.H. (1981). Lingüística Geral. Porto Alegre e Rio de Janeiro: Editora Globo.

SCHIFFER, S. (1972). Meaning. Oxford: Clarendon.

SPERBER, D. \& Wilson, D. (1986). Relevance: Communication and Cognition. Oxford: Blackwell.

TER MEULEN, Alice. (1988). 'Linguistics and the philosophy of language'. In Newmeyer, F. (ed.). Linguistics: The Cambridge Survey. Vol. 1. Linguistic Theory: Foundations. Pp. 430-440.

VERSCHEUREN, Jef. (1999). 'Whose discipline? Some critical reflections on linguistic pragmatics'. Journal of Pragmatics. Vol. 31. № 7. Pp. 869-879.

ZIZEK, Slavoj. (1994). Mapping Ideology. London: Verso. 